\title{
7 ANOS DE USO E MAIS DE 2000 MANIFESTAÇÕES PATOLÓGICAS EM CONJUNTO HABITACIONAL DE INTERESSE SOCIAL EM ALVENARIA ESTRUTURAL
}

\author{
PILZ, SILVIO E. \\ Engenheiro Civil \\ Unochapecó \\ SC; Brasil \\ silvio@unochapeco.edu.br \\ PIASESKI, FLÁ VIA M. \\ Engenheira Civil \\ Unochapecó \\ SC; Brasil \\ flaviamarinap@unochapeco.edu.br \\ BOTTEGA, GABRIELA S. S. \\ Engenheira Civil \\ Unochapecó \\ SC; Brasil \\ gabi.souza@unochapeco.edu.br
}

\author{
BATISTON, EDUARDO R. \\ Engenheiro Civil \\ Unochapecó \\ SC; Brasil \\ erbatiston@unochapeco.edu.br
}

\author{
COSTELLA, MONIKE M. \\ Engenheira Civil \\ Unochapecó \\ SC; Brasil \\ monike@unochapeco.edu.br
}

\author{
LISBOA, LEODIMAR A. \\ Engenheiro Civil \\ Unochapecó \\ $\mathrm{SC}$; Brasil \\ leodimar@unochapeco.edu.br
}

\author{
COSTELLA, MARCELO F. \\ Engenheiro Civil \\ Unochapecó \\ SC; Brasil \\ costella@unochapeco.edu.br
}

\section{RESUMO}

Historicamente, as habitações de interesse social têm sido caracterizadas como edificações construídas com qualidade inferior, em virtude do alto índice de manifestações patológicas que costumam apresentar. Em virtude disso, o objetivo deste artigo foi identificar a origem das manifestações patológicas de um conjunto habitacional de interesse social construído em alvenaria estrutural no oeste de Santa Catarina. O método de pesquisa consistiu na inspeção visual de 171 itens nos sistemas de pisos, paredes, revestimentos, esquadrias, pintura, estruturas de concreto, esquadrias, forro e instalações por meio do check list adaptado de Silveira Neto (2004). Os resultados apontaram que a parede estrutural apresentava o maior número de sintomas, seguido de piso e sistema de esgoto, os quais representavam $60 \%$ das anomalias, sendo responsáveis por mais de 1300 incidências de manifestações patológicas das 2221 encontradas. Em relação à origem das manifestações patológicas, constatou-se que 36\% estavam relacionadas a erros de execução, 29\% a falhas do projeto, $20 \%$ à fase de uso e $15 \%$ provenientes dos materiais. O ponto crítico foram patologias de cunho estrutural em estado progressivo de degradação que, mesmo assim, não havia previsão de correção, colocando em risco a segurança dos usuários.

Palavras-chave: manifestações patológicas, alvenaria estrutural, sistemas construtivos.

\begin{abstract}
Historically, social housing has been characterized as lower quality buildings, due to the high rate of pathological manifestations they usually present. Then, the objective was to identify the origin of the pathological events of a social housing project built in structural masonry in the west of Santa Catarina. The research method consisted of the visual inspection of 171 items in the systems of floors, walls, cladding, frames, painting, concrete structures, frames, lining, and installations through the adapted checklist of Silveira Neto (2004). The results showed that the structural wall presented the highest number of symptoms, followed by floor and sewerage, which represented $60 \%$ of the anomalies, accounting for more than 1300 incidences of pathological manifestations of 2221 found. Regarding the origin of the pathological
\end{abstract}


events, it was found that $36 \%$ were related to execution errors, $29 \%$ to project failures, $20 \%$ to the use phase, and $15 \%$ from materials. The critical point was structural pathologies in a progressive state of degradation that, even so, there was no prediction of correction, endangering the safety of users.

Keywords: pathological manifestations, structural masonry, construction systems.

\section{INTRODUÇÃO}

Com os investimentos realizados pelo Governo Federal para o desenvolvimento do país, o mercado imobiliário foi impulsionado na última década, aumentando as atividades da construção civil, principalmente as habitações populares. Devido à necessidade de suprir a demanda de imóveis de padrão popular, as edificações foram construídas em tempo inferior ao recomendado tecnicamente, o que contribuiu para o surgimento de milhares de manifestações patológicas (ALMEIDA, 1999; IBRACON, 2005).

Enfim, torna-se necessário efetuar levantamentos que possam caracterizar quais são estas manifestações patológicas, bem como suas origens e causas, servindo de feedback aos projetistas e construtores, de modo a evitar que incorram nos mesmos erros. Este artigo tem o objetivo de caracterizar a causa, a origem e a frequência das 2221 manifestações patológicas encontradas em um conjunto habitacional popular com idade de uso de sete anos.

\section{MÉTODO DE PESQUISA}

A pesquisa foi realizada em um conjunto habitacional no município de Xaxim, SC. Este conjunto habitacional é caracterizado como condomínio multifamiliar (Figura 1), construído no ano de 2011 com 14 blocos, composto de 4 pavimentos tipo e contendo 4 apartamentos por andar, totalizando 224 unidades. Os apartamentos possuem área privativa de $47,01 \mathrm{~m}^{2}$, sendo 14 blocos de $852,71 \mathrm{~m}^{2}$, totalizando $11.937,94 \mathrm{~m}^{2}$.

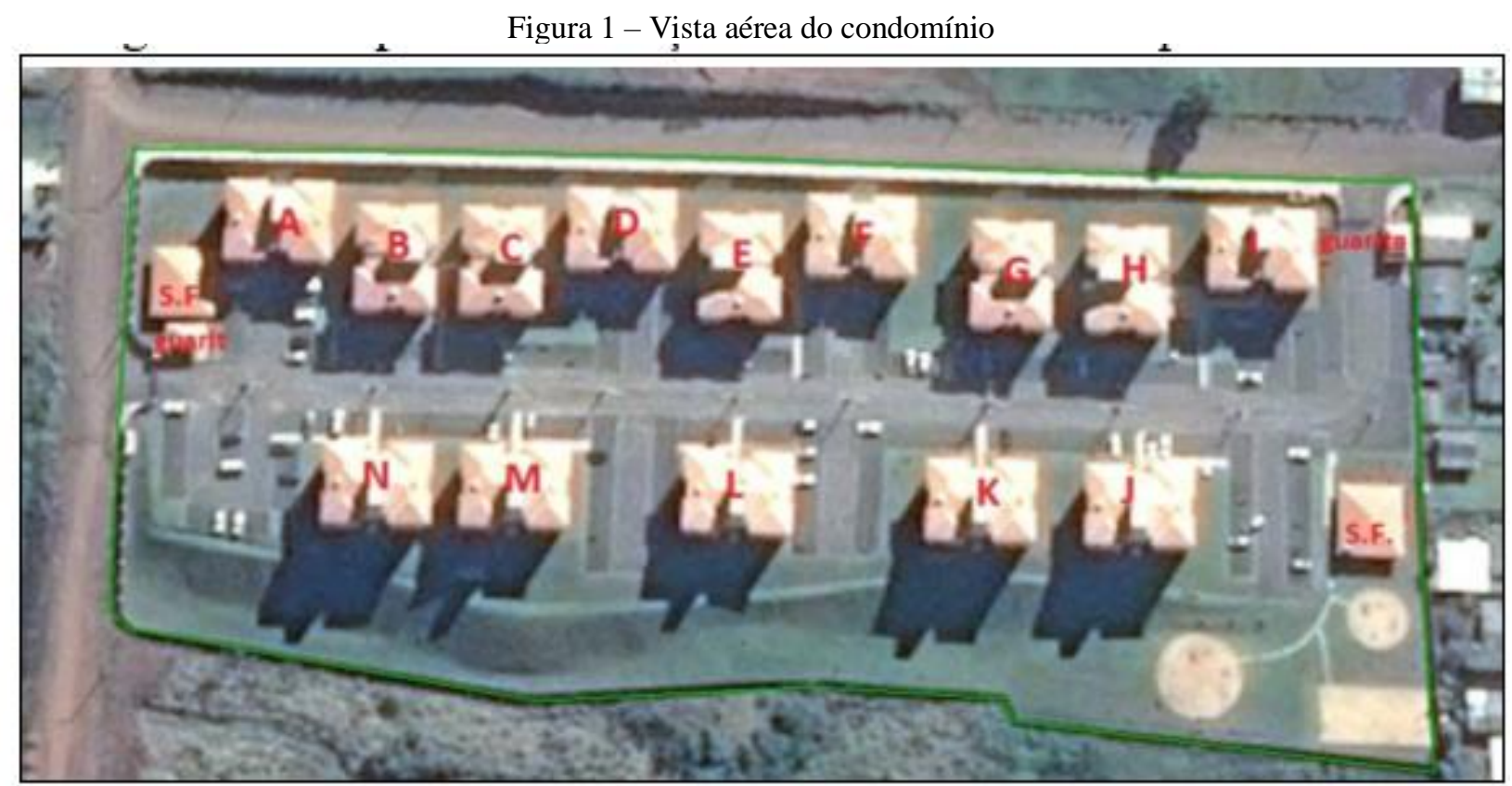

Fonte: adaptado de Google Maps (2015).

O sistema construtivo é composto de paredes de alvenaria autoportante com blocos cerâmicos, paredes de blocos cerâmicos de vedação e laje treliçada com lajotas cerâmicas. O sistema de cobertura é composto por estrutura de madeira e telhas cerâmicas. Em 2018, foram coletados dados de 112 apartamentos, representando uma amostra de 50\% das unidades do conjunto habitacional. Para a identificação das causas prováveis foi elaborada uma lista de verificação adaptada de Silveira Neto (2004) com 171 itens divididos em 9 sistemas: pisos, paredes, revestimentos, esquadrias, pintura, estruturas de concreto, esquadrias, forro e instalações. O método de levantamento de dados foi a análise visual com inspeção in loco e registro fotográfico com a localização de todos os sintomas detectados. Para efetuar a análise dos dados, além do registro fotográfico de cada ocorrência, foram agrupados os dados de acordo com o local da ocorrência (área privativa ou comum) e tipo de sistema. 


\section{APRESENTAÇÃO E DISCUSSÃO DOS RESULTADOS}

A inspeção resultou na observação de 2221 manifestações patológicas. A Tabela 1 apresenta os resultados das manifestações patológicas por incidência nos sistemas construtivos e o tipo de área (privativa ou comum). A maior incidência de sintomas nos apartamentos foi no sistema de paredes, seguido pelo sistema de pisos. Já nas áreas comuns, as manifestações patológicas ocorreram principalmente no sistema de paredes.

Tabela 1 - Resultados das manifestações patológicas por sistemas construtivos das áreas comuns e apartamentos

\begin{tabular}{|c|c|c|c|c|}
\hline Sistemas construtivos & $\begin{array}{c}\text { Apartamentos } \\
\mathbf{\%}\end{array}$ & $\begin{array}{c}\text { Área comum } \\
\mathbf{\%}\end{array}$ & $\begin{array}{c}\text { Total } \\
\mathbf{\%}\end{array}$ & $\begin{array}{c}\text { Total } \\
\text { (unidade) }\end{array}$ \\
\hline Piso & 22,17 & 11,40 & 18,60 & 413 \\
\hline Paredes & 26,15 & 30,53 & 27,60 & 613 \\
\hline Revestimento & 7,95 & 9,63 & 8,51 & 189 \\
\hline Pintura & 8,15 & 11,40 & 9,23 & 205 \\
\hline Estrutura de concreto & 7,28 & 12,48 & 9,00 & 200 \\
\hline Esquadrias & 12,33 & 3,80 & 9,50 & 211 \\
\hline Instalações & 12,87 & 12,48 & 12,74 & 283 \\
\hline Forro & 3,10 & 0,00 & 2,07 & 46 \\
\hline Cobertura & 0,00 & 8,28 & 2,75 & 61 \\
\hline Total (unidade) & $\mathbf{1 4 8 4}$ & $\mathbf{7 3 7}$ & $\mathbf{2 2 2 1}$ & $\mathbf{2 2 2 1}$ \\
\hline
\end{tabular}

Fonte: elaborado pelos autores.

Referente aos sintomas identificados nos sistemas de pisos (Figura 2), 84\% eram peças quebradas na sala e dormitórios e $44 \%$ eram falhas no rejunte.

Figura 2 - Manifestações patológicas identificadas no sistema de pisos

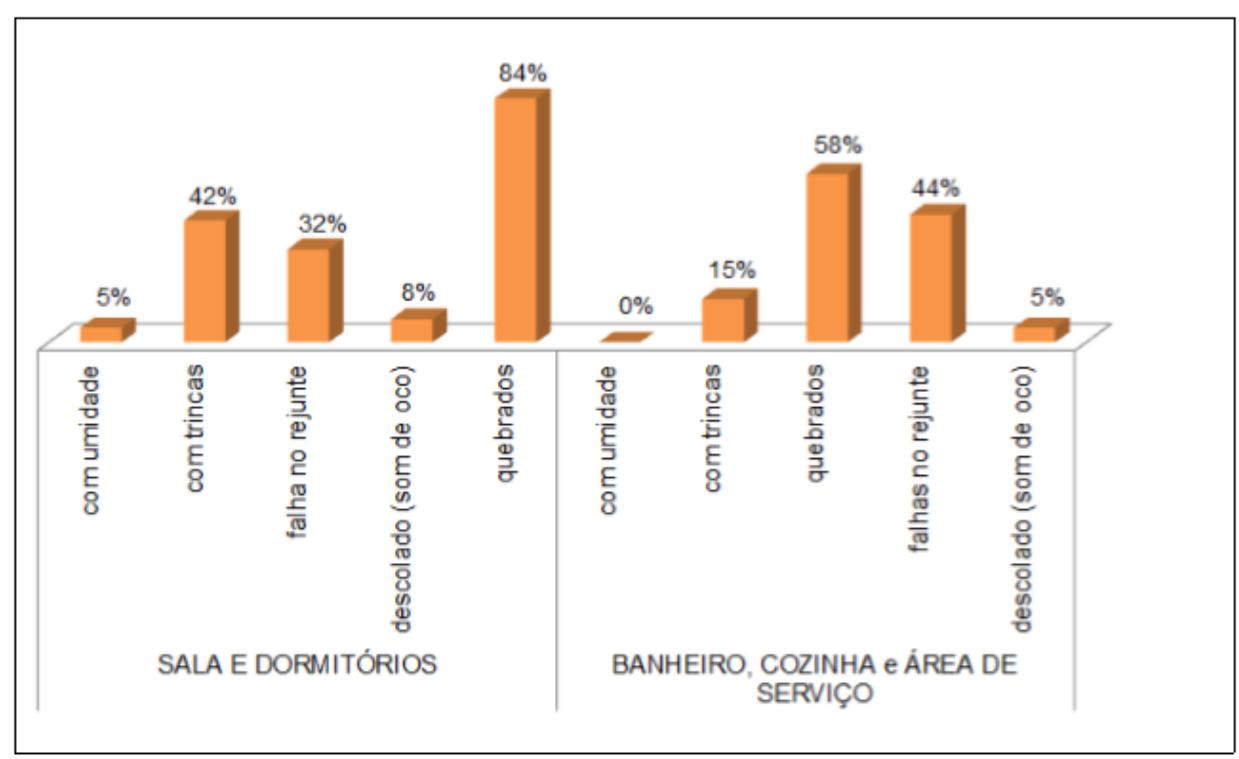

Fonte: elaborado pelos autores.

Os sintomas mais comuns encontrados no sistema de parede (Figura 3) foram trincas internas, manchas, bolor e umidade, com destaque para a elevada incidência desses sintomas junto à laje. A incidência junto às janelas também foi representativa. As causas possíveis eram oriundas da intensa umidade no substrato e da deficiência no sistema de vedação. 
Figura 3 - Manifestações patológicas identificadas no sistema de parede

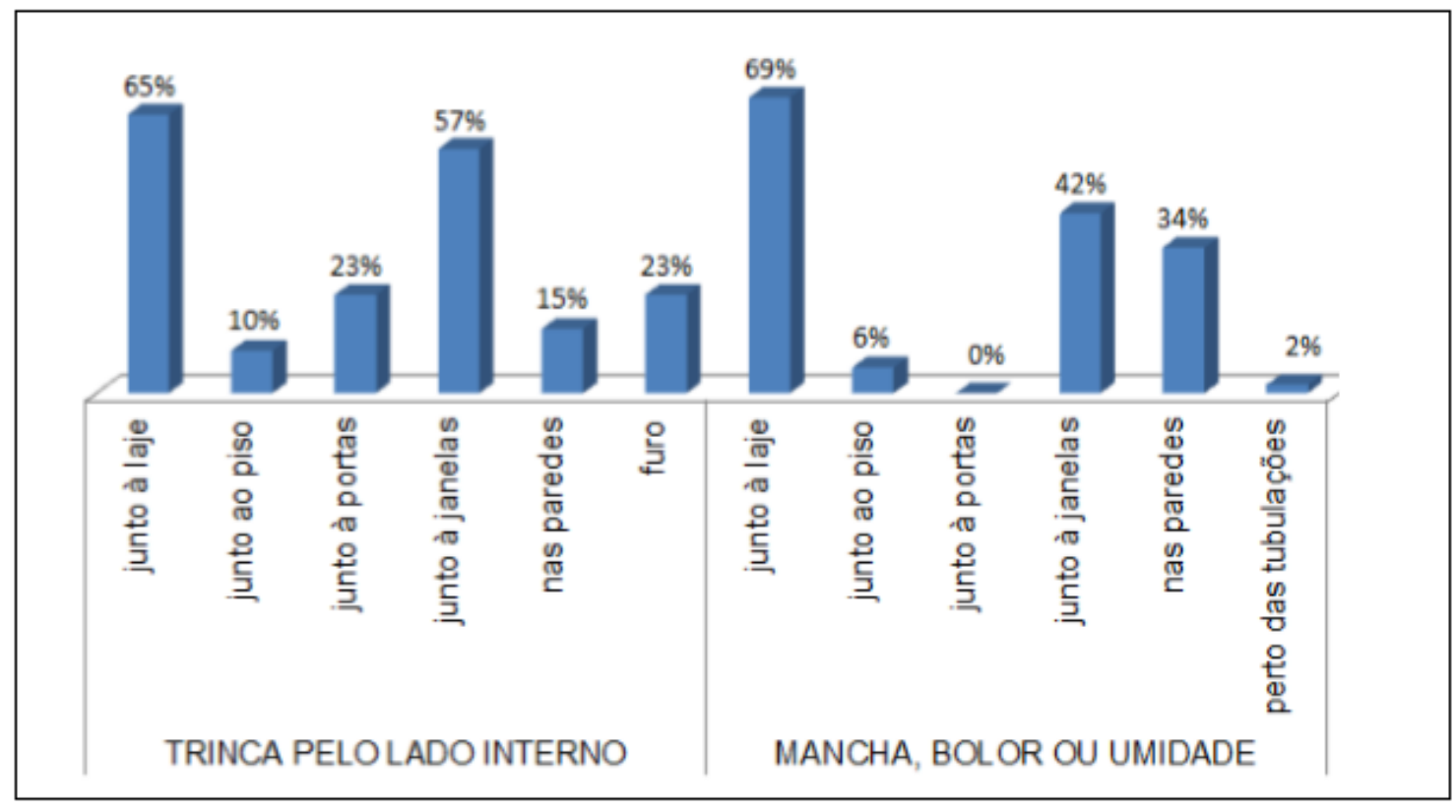

Fonte: elaborado pelos autores.

A Figura 4 apresenta as manifestações patológicas detectadas nos sistemas de revestimentos aderidos. As possíveis causas do surgimento das trincas no reboco estavam relacionadas à aplicação do revestimento em condições atmosféricas desfavoráveis. As manifestações patológicas encontradas nos azulejos e ladrilhos apresentavam descontinuidade no rejunte que, provavelmente, tiveram sua causa decorrente do uso incorreto da argamassa, variação térmica e más técnicas construtivas.

Figura 4 - Manifestações patológicas identificadas no sistema de revestimentos

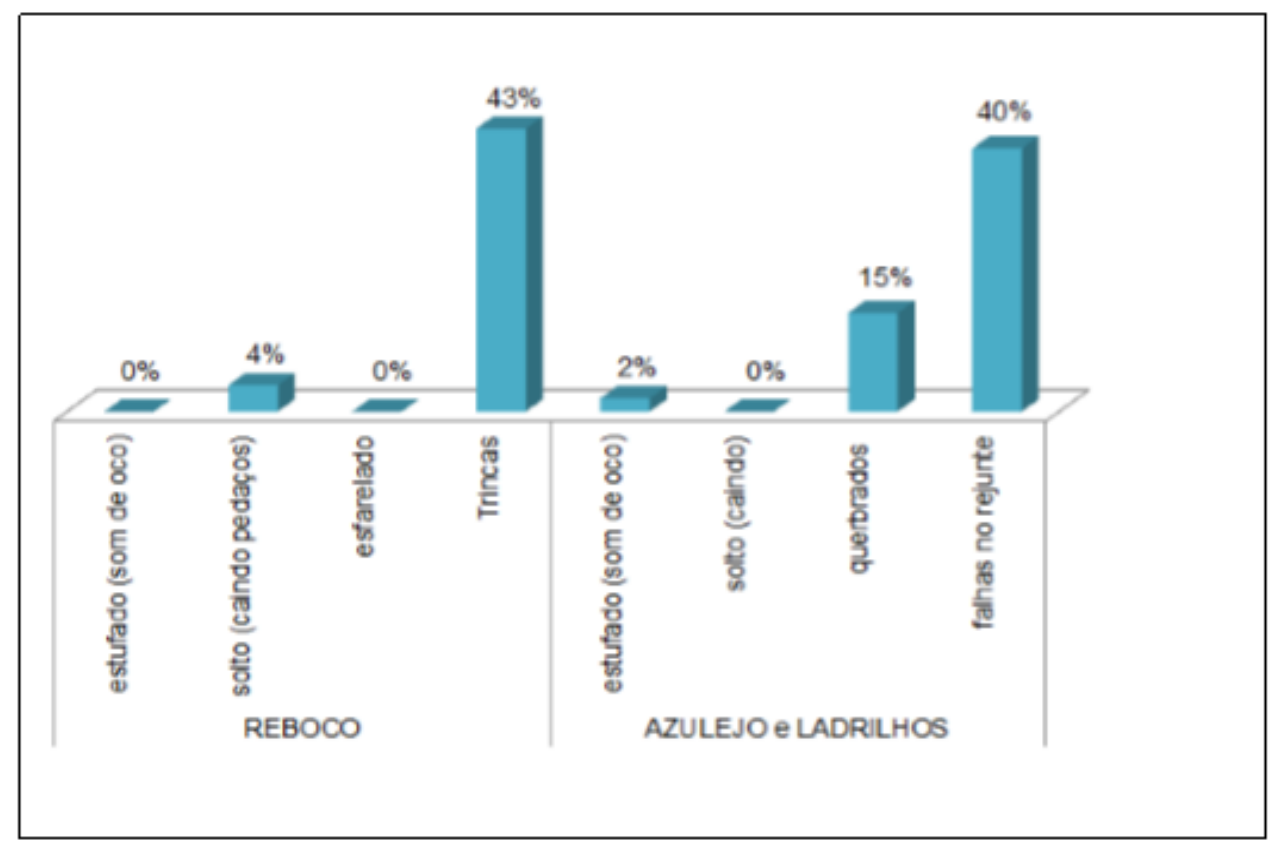

Fonte: elaborado pelos autores.

Sobre as manifestações patológicas identificadas no sistema de pintura (Figura 5), 60\% era a pintura que estava desprendendo do revestimento argamassado. Quanto às bolhas na pintura, também foi observado umidade no substrato, paredes com trincas e fissuras, além de indícios de vazamentos hidráulicos. 
Figura 5 - Manifestações patológicas identificadas no sistema de pintura

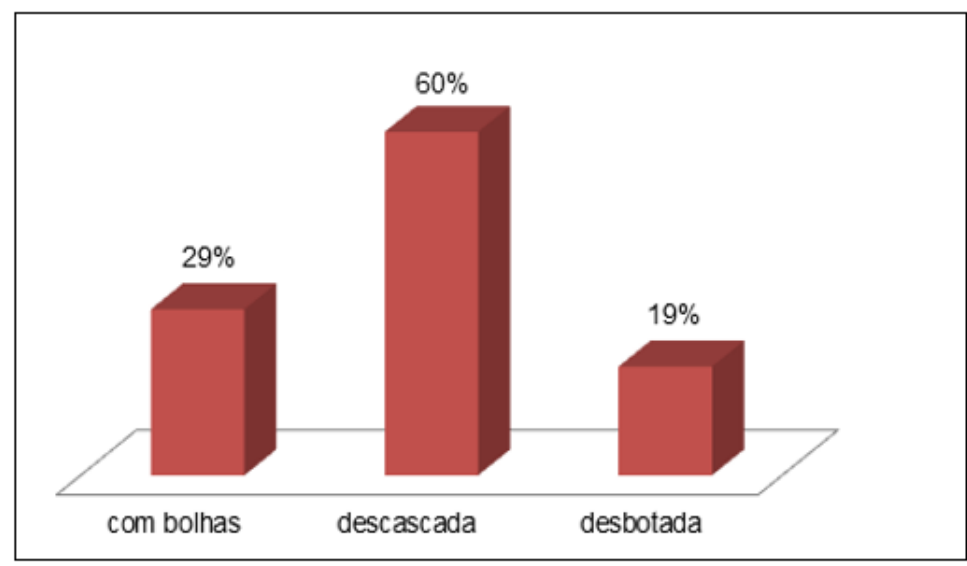

Fonte: elaborado pelos autores.

A Figura 6 apresenta as manifestações patológicas constatadas e as respectivas porcentagens para as lajes, já que não foi observado nenhum sintoma em vigas e pilares. As trincas que foram observadas no último pavimento, indicaram movimentação térmica. Outras possibilidades são redução de espessura da laje e flexão devido à insuficiência de armadura para momentos negativos, tendo como causa principal a fase de projeto. A umidade presente na laje era provocada pela infiltração de água da chuva, da rede hidráulica e potencializado pelas fissuras externas.

Figura 6 - Manifestações patológicas constatadas identificadas nas lajes

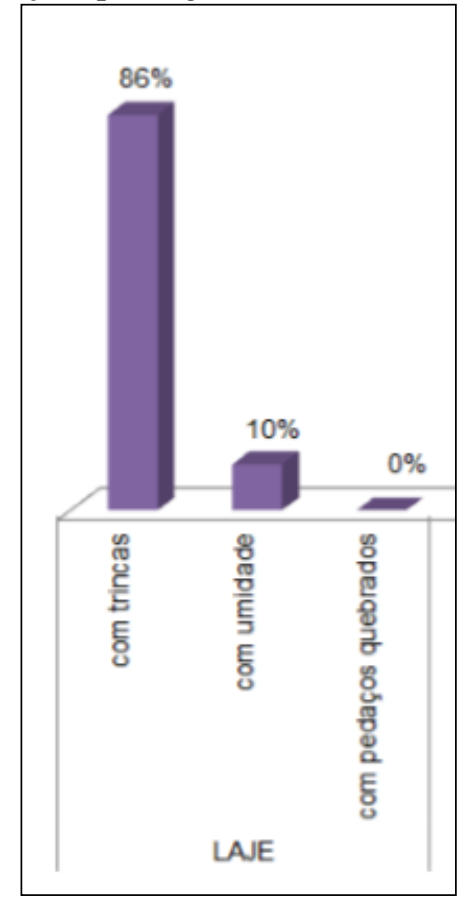

Fonte: elaborado pelos autores

A Figura 7 apresenta as manifestações patológicas constatadas e as respectivas porcentagens para os sistemas de esquadrias. As portas de madeira das edificações eram de material com baixa qualidade. As janelas apresentam componentes de fechamento mau regulados e, além disso, não havia manutenção. 
Figura 7 - Manifestações patológicas identificadas no sistema de esquadrias

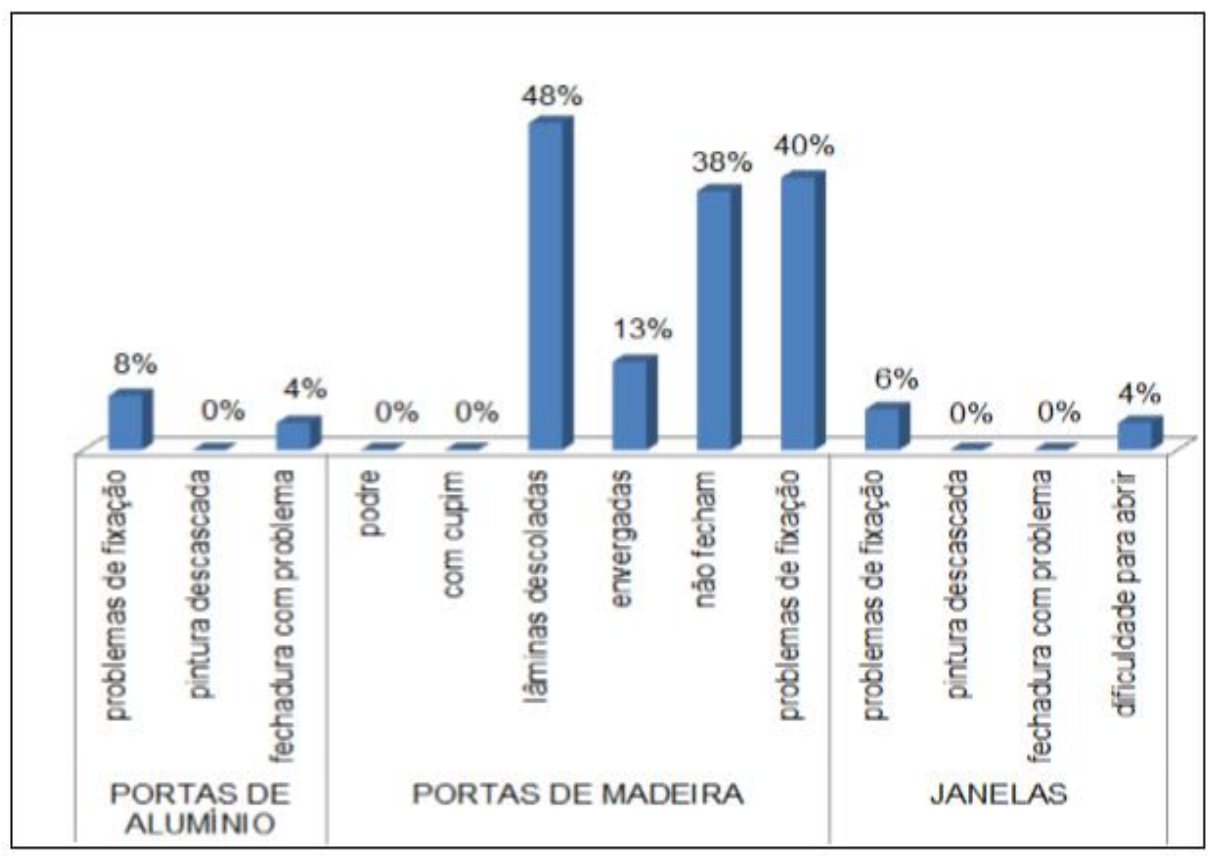

Fonte: elaborado pelos autores.

Os problemas no sistema de forro, que foi somente o forro deformado (38\%), foram ocasionados por vazamento no banheiro do pavimento superior. A Figura 8 apresenta as manifestações patológicas constatadas e as respectivas porcentagens para os sistemas de instalações. Os vazamentos nas instalações hidráulicas eram decorrentes de furo no reservatório. Verificou-se que o mau cheiro proveniente do esgoto é causado pela obstrução na tubulação de ventilação. Nas instalações elétricas, os disjuntores frequentemente se desligam devido aos equipamentos utilizados com potência acima da capacidade de segurança do disjuntor. Curto circuitos nas instalações elétricas ocorriam pela espessura dos cabos abaixo das solicitadas pelos equipamentos e, além disso, havia umidade.

Figura 8 - Manifestações patológicas identificadas no sistema de instalações

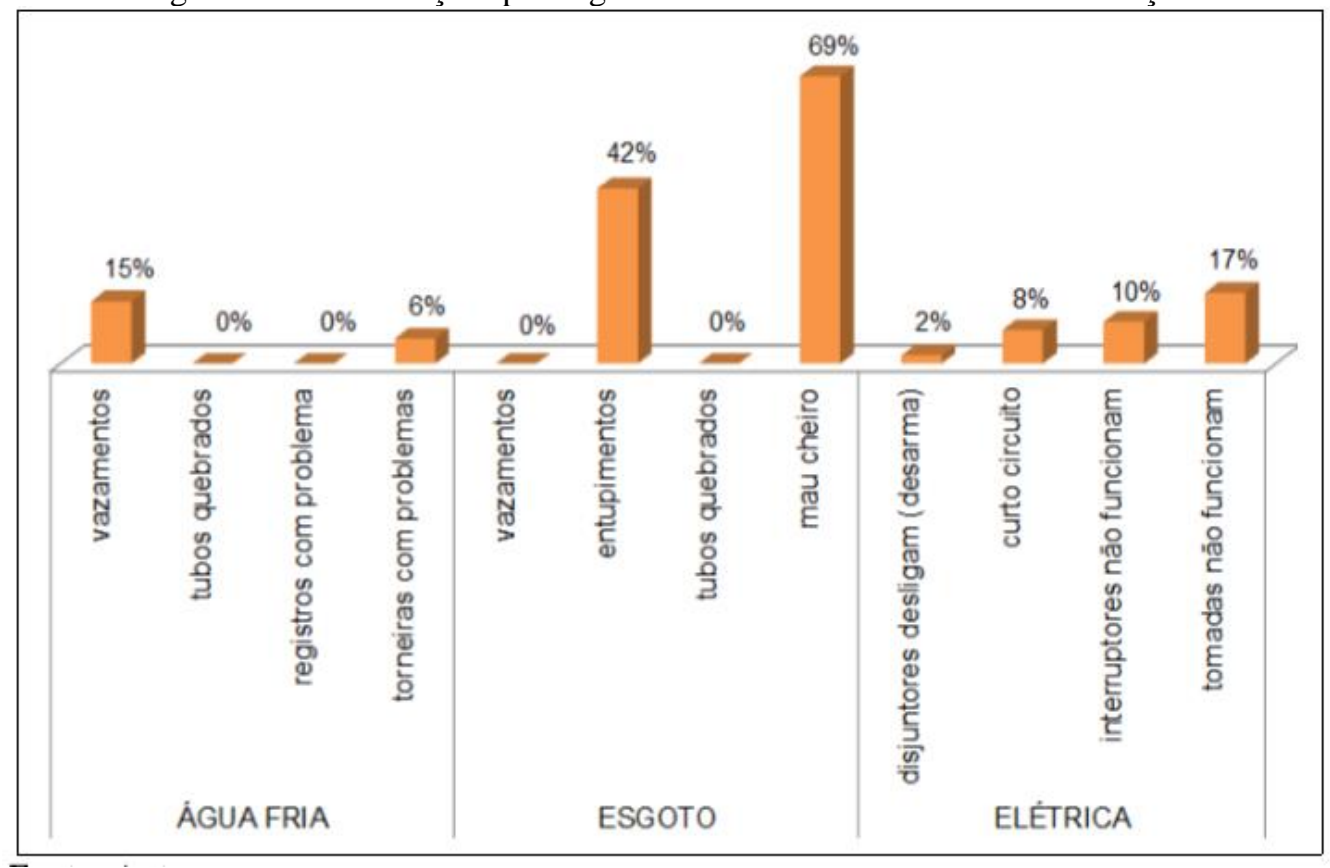

Fonte: elaborado pelos autores.

Em resumo, a origem das manifestações patológicas decorre de falhas na execução, falhas de projeto, falhas de uso e ou manutenção ineficiente e utilização de materiais de baixa qualidade, conforme representado na Figura 9. 
Figura 9 - Percentual das origens das manifestações patológicas

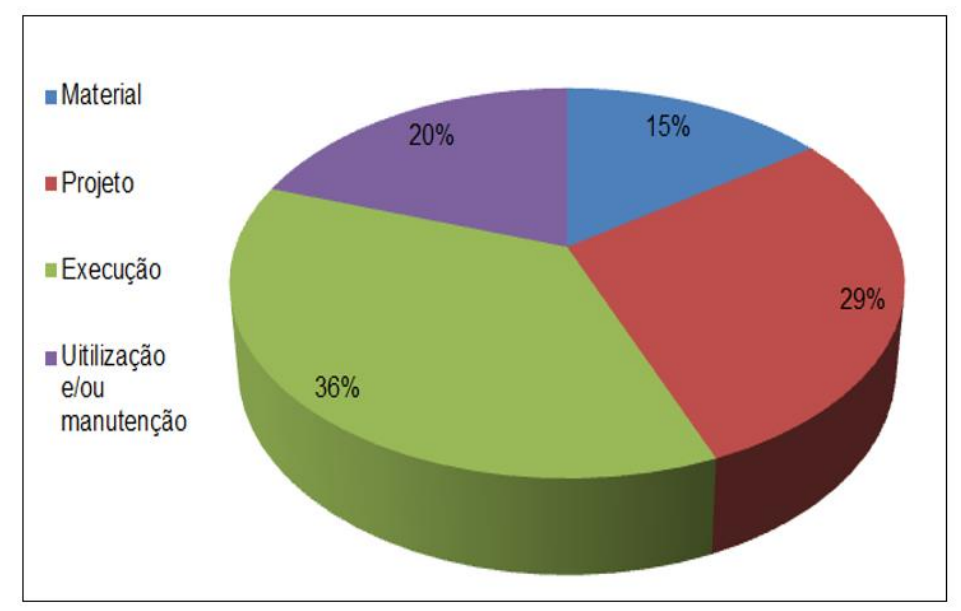

Fonte: elaborado pelos autores.

\section{DISCUSSÃO}

O Ministério da Transferência, Fiscalização e Controladoria Geral da União (CGU) emitiu um balanço dos recursos destinados ao Programa Minha Casa Minha Vida (BRASIL, 2016) para empreendimentos enquadrados na Faixa 1. O relatório aponta que foram verificadas incompatibilidades relacionadas aos quantitativos previstos e especificações em projetos em cerca de 48,9\% das unidades habitacionais, apontando como problemas mais frequentes as fissuras, infiltrações e vazamentos. Isso corrobora os achados dessa pesquisa, que apontaram 36\% das manifestações patológicas relacionadas a erros na fase de execução e $29 \%$ na fase de projeto.

Para Silva (2013), fissuras, trincas e rachaduras na alvenaria estrutural podem ser decorrentes, principalmente, de recalques nas fundações, movimentações térmicas e higroscópicas, sobrecargas, retração de elementos de concreto, deformações de elementos da estrutura, reações químicas devido à expansão da junta de argamassa, vibrações e inexatidão de detalhes construtivos. As infiltrações e vazamentos tinham sua origem em falhas de materiais, ausência de impermeabilização ou na má execução no processo construtivo (SOUZA, 2017). No entanto, esta pesquisa apontou a umidade como responsável por boa parte da degradação e ainda destacou que parte dos erros foram originados em fase de projeto com a redução de espessura da laje e a insuficiência de armadura para momentos negativos.

Oliveira, Melo e Filho (2016) identificaram as fissuras como a principal manifestação patológica devido a falhas de travamento da estrutura, ausência de juntas de dilatação, desaprumo, juntas mal executadas ou junta seca, reação química na argamassa utilizada, movimentação higroscópica, recalque de fundação, utilização de blocos quebrados, vinculação da laje de cobertura com a última fiada de tijolos, inexistência de vergas e contra-vergas e armazenamento inadequado dos blocos estruturais. Em um estudo de caso para avaliar anomalias em fachadas de habitações de interesse social executadas em alvenaria estrutural (ROCHA et al., 2018), os principais vícios encontrados foram fissuras (63\%), umidade (23\%), descolamento de revestimento (8\%) e sujidades (6\%), ocasionados pela falta de manutenção da edificação, além de falhas no projeto que não considerou alternativas devido à orientação solar das fachadas.

Enfim, os estudos discutidos anteriormente e também Bernardes (2007) e Alves, Thomé e Tosta (2017) corroboram os resultados dessa pesquisa que apontaram que a parede estrutural apresentava o maior número de sintomas, seguido de piso e sistema de esgoto, os quais representaram 60\% das anomalias, sendo responsáveis por mais de 1300 incidências de manifestações patológicas das 2221 encontradas.

\section{CONSIDERAÇÕES FINAIS}

Constatou-se que os objetivos da pesquisa foram atingidos, inclusive com um volume expressivo de manifestações patológicas (2221). Os resultados possibilitaram demonstrar os sistemas construtivos que mais apresentaram manifestações patológicas: o sistema de paredes (26\%), sistema de piso (22\%) e sistema de instalações (13\%). Quanto à origem das manifestações é possível afirmar que a fase execução da obra contribuiu para o maior número de manifestações patológicas (36\%), seguida da fase de projetos (29\%), manutenção das edificações (20\%) e seleção dos materiais (15\%).

Considerando que o conjunto habitacional não possuía plano de manutenção preventiva, quando a manutenção corretiva 
era necessária, era realizada por profissionais pouco qualificados, o que acaba por apenas mascarar, e não resolver, os sintomas. Verificou-se também que, em um dos blocos, no sistema estrutural, a laje em que os reservatórios de água estão sobrepostos encontra-se em deformação, apresentando armaduras expostas e estado de corrosão progressiva. Pode-se afirmar que tais patologias estão em estágio progressivo e avançado e, caso não seja aplicada a solução corretiva, poderão colocar em risco a segurança dos usuários.

\section{Referências}

ALMEIDA, D.F. Patologia, terapia e profilaxia nas edificações de concreto. In.: Qualidade na Construção, $\mathrm{n}^{\circ} 14,15$, 16 e 17, Ano II, 1999.

ALVES, Leandro Galli; THOMÉ, Victor Merchid; TOSTA,Joice Paiva. Manifestações patológicas em casas populares: Uma análise de custo. Revista Estudo \& Debate, Lajeado, v. 24, n. 2, 2017.

BERNARDES, Cláudio. Danos Construtivos. Construção Mercado, São Paulo, n. 72, jul. 2007.

BRASIL, Ministério da Transparência, Fiscalização e Controle Geral da União (CGU). Relatório de Avaliação da Execução dos Programas de Governo, no 65 - Integralização de cotas ao FAR, Brasília. Nov.2016. Disponível em <http:// https://auditoria.cgu.gov.br/download/9141.pdf> acesso em 02/abr/2019.

BURIM, Eduardo M. et al. Vistorias na construção civil: conceitos e métodos. São Paulo: Pini, 2009.

GOMIDE, Tito Lívio Ferreira; FAGUNDES NETO, Gerônimo Cabral P.; GULLO, Marco Antonio. Inspeção predial total: diretrizes e laudos no enfoque da qualidade total e engenharia diagnóstica. São Paulo: Pini, 2011.

IBRACON. Concreto: ensino, pesquisa e realizações. São Paulo: G. C. Isaia. 2005. 2 v.

OLIVEIRA, Francielly Djanira de; MELO, Nayane Ferreira de; FILHO, Marcio Alves de; SILVA, Juliano Rodrigues da. Principais Patologias em Edifícios de Alvenaria Estrutural. REVISTA MIRANTE, Anápolis (GO), v. 9, n. 2, dez. 2016.

ROCHA, Letícia Aguilera Larrosa da; SILVA, Vívian Michele Bandeira da; PALIGA, Charlei Marcelo; TORRES, Ariela da Silva. Levantamento de manifestações patológicas em fachadas de habitações de interesse social na cidade de Pelotas/RS: Residencial Paraíso. Revista CONSTRUINDO, Belo Horizonte. Volume 10, número 02, p. 21 - 30, Jul Dez., 2018

SILVA, L.B. Patologias em Alvenaria Estrutural: causas e diagnóstico. 2013. 76 f. Monografia (Graduação em Engenharia Civil). Universidade Federal de Juiz de Fora - UFJF. Juiz de Fora. 2013. Disponível em: <http://www.ufjf.br/engenhariacivil/files/2012/10/PATOLOGIAS-EM-ALVENARIA-ESTRUTURAL.pdf> Acesso em: 02 de abr. de 2019.

SILVEIRA NETO, O. Manifestações patológicas em condomínios habitacionais de interesse social do município de Porto Alegre: levantamento e estudo sobre a recorrência. Dissertação (mestrado). Curso de Mestrado Profissional em Engenharia. UFRGS. Porto Alegre, 2004.

SOUZA, João Augusto Carneiro de. Problemas em obras do Programa Minha Casa Minha Vida. Revista Especialize On-line IPOG - Goiânia - Ano 8, Edição no 14 Vol. 01 dezembro/2017. 